\title{
LOCKE ON REAL ESSENCES, INTELLIGIBILITY, AND NATURAL KINDS
}

\author{
JAN-ERIK JONES \\ SOUTHERN VIRGINIA UNIVERSITY
}

\begin{abstract}
In this paper I criticize the interpretations of John Locke on natural kinds offered by Matthew Stuart and Pauline Phemister who argue that Locke's Essay Concerning Human Understanding allows for natural kinds based on similar real essences. By contrast, I argue for a conventionalist reading of Locke by reinterpreting his account of the status of real essences within the Essay and arguing that Locke denies that the new science of mechanism can justify the claim that similarities in corpuscular structure imply similarities in sensible qualities. I argue further that Locke rejects as meaningless any talk of kinds that appeals to similarities among real essences. On my reading of Locke, similarities in real essences are not only irrelevant to species, but natural kind theories based on them are unintelligible.
\end{abstract}

\section{$\mathbf{J}$}

ohn Locke famously argues in Book III of his Essay Concerning Human Understanding (hereafter 'Essay') that the essences of substantial species are created by our mental acts of abstraction; nevertheless, some Locke scholars have argued that Locke is still committed to a version of natural kind realism. ${ }^{1}$ Indeed, there is some merit to the realist interpretation. Part of the role of real essences in Locke is as a theoretical posit to explain the secondary and tertiary powers of bodies. By his lights, the best physical theory we have-the mechanical natural philosophy-tells us that the corpuscular constitutions of material bodies are part of our explanatory theory of the observable qualities of bodies. Moreover, it has been commonly assumed that, for Locke, similarities in corpuscular constitutions cause similarities in observable qualities. This assumption has led Locke scholars like Matthew Stuart (1999) and Pauline Phemister ${ }^{2}$ (1990), for example, to argue that Locke left open the possibility of natural kind realism in the Essay: if we sort 
objects into species based on the similar observable qualities caused by the internal constitutions, then why can we not also say that, for Locke, natural species are clusters of similar internal constitutions that cause the similar observable qualities? As we shall see below, this story is complicated by Locke's clear rejection of the claim that objects that are phenomenally similar are also necessarily similar in their internal structure (III.x.20), but he never seems explicitly to foreclose the converse claim that similarity in internal structure typically results in phenomenal similarity, and this is precisely what is needed for Phemister and Stuart to assert their versions of species realism in Locke.

In this paper, I shall argue that there are important arguments within the Essay that foreclose this version of natural kind realism and that explain why Locke would consider these structural approaches to species to be not only unjustified but unintelligible. I will focus specifically on the arguments of Phemister and Stuart, and in §I present their accounts of Lockean natural kinds and weigh some of the evidence in favor of their interpretations. In §II, I briefly examine Locke's position on the intelligibility of the mechanical hypothesis as it relates to the explanatory and justificatory power of real essences. In §III, I argue against the claim that real essences for Locke are relativized to nominal essences. In §IV, I argue that by Locke's lights we are unable to justify a corpuscular account of natural species because similarities among corpuscular constitutions need not yield similarities in observable qualities, or vice versa, and so assumptions about the mechanical hypothesis will not license inferences from similar nominal essences to similar real essences. Finally, in $\S \mathrm{V}$, I argue that, for Locke, a theory of natural species based on real essences is unintelligible.

\section{STUART, PHEMISTER, AND 'LOCKEAN NATURAL KINDS'}

According to Matthew Stuart, "Locke ... consistently presumes that there are natural kinds. This assumption is often tacit. He simply assumes that there will be a single real essence, a single inner constitution, underlying the various objects that satisfy a nominal essence such as 'gold' or 'man"' (Stuart 1999, 289). ${ }^{3}$ Since Locke thinks of a body's inner constitution as the underlying cause of its observable qualities, it follows that "when he assumes that the objects satisfying a single nominal essence will possess the same inner constitution, this amounts to the assumption that they constitute a natural kind in Boyd and Kornblith's sense."

According to Boyd and Kornblith, a natural kind is a homeostatic cluster of properties, i.e., stable groups of coinstantiated properties that are caused by the same kind of underlying mechanism (see Boyd 1991 and Kornblith 1993). It is Stuart's conclusion that this version of natural kinds is found in Locke's Essay, that "Locke consistently presumes that regular clusters of observable qualities are the products of stable and repeated microstructures" (Stuart 1999, 280).

If this were Locke's considered view, then you would expect him to say that our nominal essence ideas are likely to track the real essences and provide us with a generally accurate judgment of the microstructural joints in nature. However, 
Stuart goes on to argue, rightly, that III.vi.13, 30, and 37, imply that "it is unlikely that our nominal essences perfectly represent the boundaries defined by real essences ... we must be awake to the possibility that there are two very different sorts of microstructures underlying the things we call 'gold"' (Stuart 1999, 290-291; see III.x.20). However, if it is possible, by Locke's lights, for there to be similar nominal essences (or perhaps similar homeostatic clusters of properties) that are not caused by similar microstructural constitutions, then it appears that Locke does not presume that regular clusters of observable qualities are the products of stable and repeated microstructures.

Stuart attempts to alleviate this tension by arguing that for Locke, "the claim that recurring clusters of observable properties are the products of recurring microstructures is one which could conceivably be justified either directly by observation, or indirectly by inference" (Stuart 1999, 292). Since Locke clearly does not believe that our presumption in favor of natural kinds is justified directly through observation, then it must be inferentially justifiable through analogical reasoning that draws upon the explanatory strength of the mechanical natural philosophy:

Sensations of heat can be caused by rubbing hands or sticks together, and Locke [in IV.xvi.12] hypothesizes that when similar sensations are caused by combustion, this is probably the result of agitation at the microscopic level. The principle underlying this analogical reasoning is that similar effects are likely to have similar causes. This is precisely the principle that is needed to justify the supposition that various objects satisfying the nominal essence of gold are likely to have similar corpuscular structures. (Stuart 1999, 293)

The plausibility of Lockean natural kinds, for Stuart, seems to rest on the important mechanistic assumption that similar effects are likely to have similar causes. We shall call this the top-down similarity thesis (hereafter 'top-down thesis'), i.e., that the observable similarities are an (perhaps fallible) indication of corpuscular or structural similarity. ${ }^{4}$ The bottom-up similarity thesis (hereafter 'bottom-up thesis'), on the other hand, would be that similar corpuscular structure is the causal source of similarities in observable qualities.

An important question here is whether one could be warranted in accepting the top-down thesis without accepting the bottom-up thesis? The question of whether the micro-structural features of distinct parcels of matter are nearly perfectly alike simply because their observable features are nearly perfectly alike is an inference that seems to be justified by a metaphysical assumption like the bottom-up thesis. To see this, we could simply ask what would justify the top-down thesis if-for the sake of argument - the bottom-up thesis were assumed to be false? In essence, there seems to be an implicit assumption (grounded within the mechanical hypothesis) about the causal powers of the microstructures that justifies the top-down thesis. So it seems that in order for Locke to allow for natural kinds à la Stuart, Locke would have to accept the plausibility of the bottom-up thesis as the justification for the top-down thesis. So in order for Stuart to make his case for the top-down thesis in Locke, he needs an argument for the ability of the mechanical natural philosophy 
in the Essay to underwrite Locke's willingness to accept the bottom-up thesis. By Stuart's lights, Locke's willingness to employ mechanical analogies from the macro-level to the unobservable micro-level justifies this kind of inference. Here he cites Locke:

Analogy in these matters is the only help we have, and 'tis from that alone we draw all our grounds of Probability. Thus, observing that the bare rubbing of two Bodies violently upon one another, produces heat, and very often fire it self, we have reason to think, that what we call Heat and Fire, consists in a violent agitation of the imperceptible minute parts of the burning matter. (IV.xvi.12; see Stuart 1999, 293)

According to Stuart, Locke thinks that the analogical use of the mechanical hypothesis justifies our causal judgments that go beyond observation. So, if like causes produce like effects at the macro-level, then, according to Stuart's Locke, analogy allows us to attribute this maxim to the sub-microscopic level as well and conclude that where nominal essences are similar, so too are the microstructures (Stuart 1999, 293).

The problem here, however, is that the causal similarity assumption is just that, an assumption, which is included within the analogy, not justified by that analogy, and it is this bottom-up causal similarity claim imbedded within the analogy that needs to be justified. Of course, while Locke would surely allow the analogical projection as an intelligible theory about the sub-microscopic domain, from this, as we shall see below, it does not follow that Locke would conclude with Stuart that this theory justifies the judgment that where nominal essences are similar so too are the real essences. As it happens, Locke has a series of arguments in the Essay that preclude Stuart's inductive approach to natural kinds.

Similarly, Pauline Phemister (1990) argues that since Locke seems to allow for the possibility of numerically distinct, but structurally identical real essences, there might be, on Locke's model, natural kinds of real essences. As she put it:

[Individuals with the same type of real essence] would then make up a natural species. They may even constitute a reasonably large species, that is, one with more than just a few members. Its members may not look identical to us but that will be because they are in different spaces and times and have different relations to the things around them and not because they have different real essences. Their real essences might actually be identical and there might therefore be essences of species. (Phemister 1990, 52)

So, she argues, similarity in real essences is sufficient for natural species of real essences. For these to be natural species for Locke, however, they should also share their observable qualities:

If substances are investigated thoroughly, they may be found to displayas the chemists often find-different qualities. In these cases, it would be legitimate to claim that external differences reflect differences in the internal real essences. On the other hand, perhaps, even when all the tests that we can think of have been done, no differences are found. In this case, it would be 
reasonable to conclude that, in all probability, there are natural real essences of [nominal essence determined] species. (Phemister 1990, 53)

In this case, where thorough investigation has shown that two individuals have all their observable qualities in common, then the reasonable conclusion is that they are members of the same natural kind based on real essence types.

It seems, then, that Phemister too is arguing for the top-down thesis, and, as we saw above, in order for the top-down thesis to be plausible for Locke, the bottom-up thesis too must be acceptable. Thus, in order to see whether Phemister's top-down conclusion reflects Locke's considered opinion, we shall have to say more about Locke's views on real essences and the explanatory role of the mechanical hypothesis. Nevertheless, one might argue that there is some powerful evidence that Locke accepted the kind of position for which Stuart and Phemister are arguing. ${ }^{5}$

For example, in III.vi.36 Locke says "Nature makes many particular Things, which do agree one with another, in many sensible Qualities, and probably too, in their internal frame and Constitution." In his correspondence with Stillingfleet, he makes a similar claim:

[T]aking man, as your lordship does here, to stand for a kind or sort of individuals; all which agree in that common, complex idea, which that specific name stands for; it is certain that the real essence of all the individuals, comprehended under the specific name man, in your use of it, would be just the same, let others leave out or put into their complex idea of man what they please; because the real essence on which that unaltered complex idea, i.e., those properties depend, must necessarily be concluded to be the same. (Locke 1829 IV, 89)

Similarly, in a letter to Molyneux, Locke says:

I hope I have no where said, there is no such sort of creatures in nature as birds; if I have, it is both contrary to the truth and to my opinion. This I do say, that there are real constitutions in things from whence these simple ideas flow, which we observ'd combined in them. And this I farther say, that there are real distinctions and differences in those real constitutions one from another; whereby they are distinguished one from another, whether we think of them or name them or no. (Locke 1829 IV, 626)

Indeed, there are passages where Locke speaks of the "imperfection" of our species ideas and the need to make them better conform to nature. For example, in III. vi.31, Locke says that "this complex Idea [nominal essence], wherein they observe several Individuals to agree, is, by different Men, made very differently; by some more, and others less accurately." In III.xi.24 he says that:

And therefore in Substances, we are not always to rest in the ordinary complex Idea, commonly received as the signification of that Word, but must go a little farther, and enquire into the Nature and Properties of the Things themselves, and thereby perfect, as much as we can, our Ideas of their distinct Species. ${ }^{\text {? }}$ 
There is no reason, so one may argue, to suspect that our species ideas could be either perfected or imperfect if there is no natural species archetype like Phemister's or Stuart's. ${ }^{8}$

The problem is, however, that the above quotations are not as telling as they prima facie appear to be. First, regarding the quotation from III.vi.36, Locke's use of 'probably' when he says "and probably too, in their internal frame and Constitution" seems to indicate a nescience of the relations between the deep structure and the qualities. If Locke were convinced that the discoverable qualities reliably tracked the deep structures, then he might have said that at this point. What makes it "probable" in III.vi.36 is that the most intelligible theory we have- the mechanical hypothesis-says that differences in the real constitutions ought to create differences in the discoverable qualities, not that Locke thinks that this correlation can be known to obtain. ${ }^{9}$

As for the Stillingfleet letter, Matthew Stuart cites this passage when he argues that Locke thinks that similarity of nominal essence is explained by similarity of deep structure. Nevertheless, Stuart is quick to note that Locke immediately points out that this correspondence between sameness of discoverable qualities and sameness of real constitution is itself a natural supposition we make, but it is only its status as an hypothesis derived from the corpuscular natural philosophy that makes it "probable," not the evidence we have for it: "where we find all the same properties, we have reason to conclude there is the same real, internal constitution, from which those properties flow" (Locke 1829 IV, 91; Stuart 1999, 291-292). We have reason to suppose that observable differences track unobservable structural differences in the bodies because of the intelligibility of the mechanical hypothesis, not because there is a way to achieve certainty in this matter. ${ }^{10}$

We know this statement of what we have reason to suppose does not reflect Locke's own view because of how he phrases his reply: "it is certain that the real essence of all the individuals, comprehended under the specific name man, in your use of it, would be just the same" (Locke 1829 IV, 89, my emphasis). It is Stillingfleet's understanding of real essences that is being discussed, not strictly Locke's. That also explains why his later reply drops the language of "certainty" and contains a reminder that the assumed correspondence of real essences, where there is sameness of observable properties, is an hypothesis (Locke $1829 \mathrm{IV}, 91$ ). It seems, then, that in his letter to Stillingfleet, Locke accepted arguendo that sameness of nominal essence was grounded in sameness of real essence, but, as I shall argue below, this is not Locke's considered view.

Moreover, the letter to Molyneux contains two main claims: (i) "there are real constitutions in things from whence these simple ideas flow, which we observ'd combined in them;" and (ii) "there are real distinctions and differences in those real constitutions one from another; whereby they are distinguished one from another, whether we think of them or name them or no." The first claim only says that anything we classify has an internal constitution that is causally relevant to the qualities by which we classify. On its own, this does not imply that where there 
is a similar set of nominally essential qualities there is a similar real constitution. The second claim only implies that the real constitutions of two particulars are distinguishable — presumably by their composition—not that there are natural kinds of real constitutions.

Finally, regarding the perfection, or imperfection, of our nominal essences, there is nothing in the passages to imply that there are external species archetypes. There are, however, clues that we could perfect the nominal essences relative to our uses of those terms: our individual nominal essence ideas are frequently different from others' (which causes confusion); there are ways to make previously unnoticed sub-distinctions among the current taxonomy that reflect real differences in the samples; there are also heretofore unnoticed qualities of the physical instances of our sorted species that we could include within our nominal essences. These would all constitute a "perfecting" of the intentions and extentions of our terms, not necessarily an increasing approximation to an objective natural kind.

\section{MECHANISM, INTELLIGIBILITY AND THE LIMITS OF MECHANICAL EXPLANATIONS}

Even though the above proof texts are not sufficient to show that Locke accepted natural kinds, there are better reasons to reject natural kinds as being compatible with Locke's arguments in the Essay. In order for either the bottom-up or the top-down theses to be attributable to Locke, and therefore show that Locke countenanced one of the above versions of natural kinds that are caused by similar internal corpuscular constitutions, it has to be the case that Locke thought that the mechanical hypothesis could indeed justify this sort of inference, as Stuart maintains, by analogy. More importantly, if the mechanical hypothesis is to bear the justificatory weight of a metaphysic of natural kinds based on similarities among sensory ideas, it must be the case that Locke thought that the new science of mechanism was capable of justifying the relevant causal assumptions. If, however, Locke did not think that the new science of mechanism could justify both the causal assumptions within either the bottom-up or top-down theses, and thus the causal assumptions within the analogical projection, then the case for Stuart's and Phemister's accounts of Lockean natural kinds becomes more tenuous.

While Locke's citations of the mechanical hypothesis as both intelligible and more rational than its Scholastic rival are well known, ${ }^{11}$ he does make an important distinction between the intelligibility of the theory and its ability to deliver the truth about causation. The intelligibility of the mechanical hypothesis for Locke lies in the empirical adequacy of its explanatory concepts, not in its ability to render causal relations intelligible. Since we are empirically acquainted with the primary qualities of size, shape, motion, solidity, etc., and we are also familiar with the results of impact on observable physical bodies, then mechanical explanations are intelligible to us because they attempt to explain the secondary and tertiary qualities in terms of other features of bodies that are also familiar to us from experience. This is what Lisa Downing refers to as a sensory condition in Locke (Downing 
1998, 396-397); our intelligible concepts are grounded in the simple ideas derived from sense perception.

This helps explain why Locke argues that knowledge of the mechanical effects of bodies would be possible if we had epistemic access to the primary qualities of their internal constitutions:

I doubt not but if we could discover the Figure, Size, Texture, and Motion of the minute Constituent parts of any two Bodies, we should know without Trial several of their Operations one upon another, as we do now the Properties of a Square or a Triangle. Did we know the Mechanical affections of the Particles of Rhubarb, Hemlock, Opium, and a Man, as a Watchmaker does those of a Watch, whereby it performs its Operations; and of a File, which by rubbing on them will alter the Figure of any of the Wheels, we should be able to tell beforehand that Rhubarb will purge, Hemlock kill, and Opium make a Man sleep; as well as a Watch-maker can, that a little piece of Paper laid on the Balance will keep the Watch from going till it be removed; or that, some small part of it, being rubb'd by a File, the Machin would quite lose its Motion, and the Watch go no more. (IV.iii.25)

That is, knowledge of the primary qualities of substances would provide us some knowledge of their tertiary qualities, i.e., the power of the primary qualities of one body to alter the observable primary qualities of another body. ${ }^{12}$ It is important to note here that Locke does not say that the knowledge acquired from knowing the primary qualities of the inner constitutions would render intelligible how the primary or tertiary qualities of the bodies yield their effects, only that we would be able to infer what their effects should be; and this suggests that he thought of these judgments as based on our familiarity with the kinds of interactions involved in body-body causation.

Thus, the reason knowledge of the primary qualities of, for example, hemlock and humans, would yield a priori knowledge of the effects of hemlock on humans is because the interactions of their particles are understood purely in terms of their familiar, i.e., empirically grounded, physical and geometrical properties, just as the relationship between a lock and a key is understood purely in terms of their physical and geometrical properties; we can imagine the physical effects certain kinds of bodies will have on each other by understanding their physical features and their motions because we have previously observed similar kinds of interactions. So, for Locke, mechanical explanations that appeal to the kinds of entities or processes that are empirically grounded are intelligible. ${ }^{13}$ And this suggests that for Locke, as Downing put it, there are conceptual conditions for intelligibility: sensation grounds the concepts that we take to constitute the limits of explanation that go beyond experience (Downing 1998, 397-400).

The reason mechanical explanations are intelligible when attributed by analogy (as in Stuart) to the corpuscular level is that both the explanans and explananda meet Locke's empirical and conceptual conditions for intelligibility. The epistemic upshot is that explanations that appeal to these kinds of physical events-even at 
the sub-microscopic level—are intelligible; putative explanations that fail to appeal to empirically grounded entities or processes are thus unintelligible. By satisfying both Locke's familiarity and conceptual conditions, we can see why Locke would think of the mechanical hypothesis as the most intelligible theory possible.

However, as Margaret Wilson has argued, there is an important caveat that Locke inserts here: "the phenomena of nature are not in general intelligible through Boylean (i.e., mobility, texture, structure, collision, size, shape, etc.) concepts alone" (Wilson 1979, 147). According to Wilson, Locke thinks that "most of what goes on in the world is incomprehensible from the point of view of Boylean mechanism" (Wilson 1979, 146). In particular, in II.xxiii.23-24 Locke points out that the cohesion, continuity and extension of corporeal substances are all unintelligible to us. Moreover, in II.xxiii.28 he argues that how a transfer of motion via impulse occurs is also unintelligible to us. In the fourth edition of the Essay, Locke changed the wording of II.viii.11, deleting the claim that "[bodies operate on one another] by impulse, and nothing else" and substituted the claim that impulse is the only conceivable way bodies can interact. He did this because the phenomenon of gravity, "which is inexplicable by us" (Locke 1829 III, 304) ${ }^{14}$ is a datum for which any theory must account. What makes gravity inexplicable is our inability to conceive how a body by means only of its familiar features, e.g., size, shape, motion, solidity, etc., can attract another body. To say, however, that impulse is the only conceivable way to explain how bodies interact is not the same as to say that it is the only way that bodies $d o$ interact. This inability of impulse to explain gravity, cohesion, transfers of momentum, etc., shows that what is true of body-body causation is not fully captured in mechanical explanations.

Locke also famously argues that the causal connections between the primary qualities of bodies and our ideas of secondary qualities are irredeemably unintelligible to us. ${ }^{15}$ Since the primary qualities are the fundamental causal and explanatory concepts in the mechanical natural philosophy, then it follows that for Locke most of what we observe in nature and use in our mechanical explanations of how nature operates is unintelligible to us; we lack the ideas that would explain to us how these facts obtain.

Thus, Locke takes it that the mechanical appeal to the structures and operations of sub-microscopic particles is intelligible only insofar as it appeals to the kinds of entities and operations with which we are familiar from experience, but they are unintelligible to the extent that they fail to provide an account of how the physical features of solid particles produce their effects. Causation remains in the dark. So while analogy (as illustrated in IV.xvi.12) allows us an intelligible way to talk about entities and events that we cannot observe (whether true or false), the causal connections are necessarily unknowable and so cannot be rendered intelligible even by the analogy. Contrary to Stuart, then, it is not Locke's view that analogy will justify the relevant similarity assumption.

Moreover, as Wilson (1979), Downing (1998) and Rozemond and Yaffe (2004) $)^{16}$ have shown, it is also clear that Locke is not arguing for the truth of the mechanical 
hypothesis; the superior intelligibility of an explanatory theory and its truth are distinct virtues, and Locke has only argued for the former. ${ }^{17}$ In fact, it would be odd for Locke to claim that the corpuscularian hypothesis is true when, as we saw above, he has clearly argued that it cannot explain most of what it was intended to. It is the intelligibility of the ontology of the mechanical hypothesis that does all of the philosophical work for Locke, not its supposed truth or ability to explicate the causal relations among bodies. ${ }^{18}$

If an explanatory theory can be intelligible without being the whole truth, and Locke shows that there are a number of significant conceptual holes in the crucial causal aspect of the theory, it seems plausible to think that Locke was in fact arguing that there is some philosophical work that the mechanical hypothesis cannot do. In particular, because the explanatory gaps in mechanism occur precisely where a mechanistic account of either top-down or bottom-up causation would need them, i.e., an intelligible account of causation, it cannot justify the kinds of inferences that species realists—along with Stuart and Phemister-want to make.

Of course, this is not news; Locke's skepticism about causal connections within mechanism is well known. More importantly, Stuart and Phemister both note in their arguments that Locke is careful not to completely embrace the top-down and the bottom-up theses because they do not always hold true. Nevertheless, both agree that the top-down thesis is warranted for Locke because of the strength of the mechanical natural philosophy (the bottom-up thesis), and so, both agree that in the cases where extensive testing has shown all the observable qualities of two individuals to be the same, then the internal constitutions are likely to be the same. ${ }^{19}$ As we have seen, however, the mechanical hypothesis is unintelligible precisely where the top-down and bottom-up theses require it as their justification. There are, moreover, important Lockean reasons for thinking that real essences cannot play either a causal or a justificatory role in any account of physical species.

Before we see the argument for this, however, I should point out the familiar reasons why Locke rejects species of real essences. First, according to Locke, we have no ideas of real essences: "we [cannot] rank, and sort Things, and consequently (which is the end of sorting) denominate them by their real Essences, because we know them not" (III.vi.9). Secondly, Locke argues that even if we did have knowledge of the deep structure of bodies, no feature of that structure could be part of our species ideas until we made it one:

For what is sufficient in the inward Contrivance to make a new Species? There are some Watches, that are made with four Wheels, others with five: is this a specifick difference to the Workman? Some have Strings and Physies, and others none; some have the Balance loose, and others regulated by a spiral Spring, and others by Hogs Bristles: Are any, or all of these enough to make a specific difference to the Workman, that knows each of these, and several other different contrivances, in the internal constitutions of the Watches? 'Tis certain, each of these hath a real difference from the rest: But whether it be an essential, a specifick difference or no, relates only to the complex Idea to which the name Watch is given. (III.vi.39) ${ }^{20}$ 
That is, knowledge of internal structure would not tell us what features constitute differentia, rather, we have to decide which features are to be included in the definitions of our species terms. This shows that even if the primary qualities of the minute particles were discoverable ${ }^{21}$ it would still not give us any insight into the essential features of the kind because the same choices of what to include in our definitions would resurface at the microscopic level. This is why for Locke, "Essence, even in [the sense of real essence], relates to a Sort, and supposes a Species" (III.vi.6); if we were to discover the structural features of a parcel of gold that produce its nominally essential properties, we must have previously identified it as gold, and thus have already identified which qualities are going to be considered as essential and which accidental to this parcel of matter qua instance of gold. Thus, only the nominal essence determines species membership because a quality is only accidental or essential to an individual once we have referred it to a species. It follows that no particular features of the corpuscular structure on their own determine the species. This is why both Stuart and Phemister focus on the inference from nominal essence determined species members to similarities in real essences.

Finally, as we shall see below, another reason Locke thinks species are the workmanship of the understanding rests on his conclusion that the more incurable part of our ignorance of real essences stems from the limits of their supposed explanatory role within the mechanical natural philosophy. ${ }^{22}$

\section{NON-RELATIVE REAL ESSENCES}

Before fleshing out these arguments in Locke, however, it will be useful to reveal more about the position on real essences with which Locke is working. And with that, a brief caveat is in order: I am not arguing that Locke thinks of real essences as part of the truth about nature, rather my argument below is that he thinks the concept of real essence is intended to play an important explanatory role in the mechanical natural philosophy, and it is his concern to see how much explanatory power the concept has, not to argue for its truth or philosophical adequacy. So, while I shall use expressions like 'Lockean real essence,' I am only referring to the concept as Locke understands it, I am not assuming it is an ontological commitment of his. ${ }^{23}$ With this in mind, we shall look more closely at what Locke takes a real essence to be.

Some scholars, including Stuart and Phemister, argue that the concept of real essence in Locke consists solely in the subset of the physical constitution that is responsible for the nominally essential properties. Here is a proof-text:

By this real Essence, I mean that real constitution of any Thing, which is the foundation of all those Properties, that are combined in, and are consequently found to co-exist with the nominal Essence. (III.vi.6) ${ }^{24}$

But it is also clear that Locke refers to the real essences of unsorted individuals, that is, the real essences of things prior to our ranking them under names: 
First, Essence may be taken for the very being of any thing, whereby it is, what it is. And thus, the real internal, but generally in substances, unknown Constitution of Things, whereon their discoverable Qualities depend, may be called their Essence. This is the proper original signification of the Word, as is evident from the formation of it; Essentia, in its primary notation signifying properly Being. And in this sense it is still used, when we speak of the Essence of particular things, without giving them any Name. (III.iii.15) ${ }^{25}$

Speaking of real essences independently of sortal terms shows that the concept of real essence that he is dealing with is not exclusively reserved for sorted individuals. It follows then that by Locke's lights real essences are not, strictly speaking, only the subsets of the real constitutions that underlie the nominally essential qualities for there are no nominally essential qualities for unsorted individuals.

More importantly, Locke also talks about the real essence of gold as "the insensible parts of that Body, on which those [nominally essential] Qualities, and all the other Properties of Gold depend" (III.vi.2). If the real essence were restricted to that subset of the real constitution that causes the nominally essential properties, then it would be strange to refer to the real essence as the cause of the properties not included within the nominal essence. In virtue of what could they be properties? ${ }^{26}$ The answer is that the real essences for sorted individuals can be distinct from those of unsorted individuals. There are two distinct parts within the canonical definition of real essences in III.iii.15: (i) 'essence' refers to what makes a thing what it is; and (ii) in substances, it is the deep structure that accounts for the qualities of the object. Locke takes it that the internal constitution makes an individual thing what it is by being its individual constitution. An unsorted individual is the individual that it is because of its constitution, which also causes all of its qualities; qua individual it has a real essence. However, in III.vi.4 he reminds us that this essence is not species determining because there is nothing essential to an individual (regarding its species) qua individual: "[No quality is] essential ... to any Individual whatsoever, till the Mind refers it to some Sort or Species of things; and then presently, according to the abstract Idea of that sort, something is found essential." Once we ask the question of what kind of thing an object is, then the real essence in this sense presupposes a sort; the real essence of this ring qua piece of gold will differ from the real essence qua particular physical object. This is why Locke later says, when talking about sorted individuals: "By this real Essence, I mean that real constitution of any Thing, which is the foundation of all those Properties, that are combined in, and are consequently found to co-exist with the nominal Essence" (III.vi.6). Once we sort a thing into a species by its nominally essential properties, then its real essence, qua member of that species, will be the collection of the real constitution that causes its nominally essential properties. Its essential properties and kind status, however, are not determined by the individual real essence in se. Thus, Locke's point is that real essences do no sorting work because the questions of essential properties and species cannot arise at the level of real essences (III.vi.4-5). 
Returning to the limited explanatory role of real essences, in III.iii.15, Locke recognizes the theoretically important nomological connection within corpuscularianism between the internal constitutions and the discoverable qualities of bodies and includes it within his description of the explanatory role of real essences. Real essences are those structures along with their necessary connections to the observable properties by reference to which we classify. ${ }^{27}$ Indeed, it appears that this is the crucial feature of Locke's distinction between real essences and the internal constitutions. For Locke, the causal connection between the internal constitutions of the real essences and the resulting qualities within the mechanical natural philosophy has some strong implications:

Had we . . . the specifick Ideas of [substances'] real Essences in our own Minds ... to know the Properties of Gold, it would be no more necessary, that Gold exist, and that we should make Experiments upon it, than it is necessary for the knowing the Properties of a Triangle, that a Triangle should exist in any Matter, the Idea in our minds would serve for the one, as well as the other. (IV.vi.11)

According to Locke, the mechanical theory seems to imply that knowledge of the real essence of any particular sorted object should enable us to deduce a priori all of its properties. ${ }^{28}$ But this should only be possible if a body's real essence included both its physical structure and that structure's necessary connection to the resulting qualities:

Other Spirits, who see and know the Nature and inward Constitution of things, how much must they exceed us in Knowledge? To which if we add larger Comprehension, which enables them at one Glance to see the Connection and Agreement of very many Ideas. (IV.iii.6) ${ }^{29}$

To have this knowledge one must know the nature and inward constitution; if the ideas of real essences are simply ideas of an arrangement of particles, then neither God nor any mind could determine a priori any of the effects of that particular structure. Thus, the concept of real essence-if it is to perform its explanatory role in a distinct way from the internal constitution-must include a causal connection between the internal constitution and the resulting qualities, and this is an important part of why he thinks we necessarily lack knowledge of real essences but not of internal constitutions. ${ }^{30}$

\section{REAL ESSENCES AND SPECIES: THE IRRELEVANCE OF STRUCTURAL SIMILARITIES}

As we saw above, within the top-down thesis of Stuart and Phemister, there is an assumed nomological connection between the primary qualities of the deep structure and the secondary qualities, such that we may justifiably identify things as belonging to the same class by reference to their phenomenal similarities. Thus, for Stuart and Phemister, similarities in deep structure (and hence similarities in their observable effects) ought to account for sameness of real essence and thus 
sameness of natural species. As we shall see below, however, for Locke we lack adequate justification for the assumption that phenomenal similarities track corpuscular similarities or vice versa.

According to Locke, the source of our ignorance of real essences primarily involves our ignorance of these deep structures cum their causal connections to the observable qualities:

Besides this Ignorance of the primary Qualities of the insensible Parts of Bodies, on which depend all their secondary Qualities, there is yet another and more incurable part of Ignorance, which sets us more remote from a certain Knowledge of the Co-existence, or Inco-existence (if I may so say) of different Ideas in the same Subject; and that is, that there is no discoverable connection between any secondary Quality, and those primary Qualities that it depends on. (IV.iii.12) ) $^{31}$

There is no discoverable connection between the two fundamental explanatory entities within the mechanical hypothesis, i.e., the primary qualities that comprise part of the concept of real essences and the secondary quality ideas that comprise part of our nominal essences. ${ }^{32}$ This is why Locke thinks that the inference from observed similarities to similarities in real constitution-the top-down thesis-fails:

The Ideas that our complex ones of Substances are made up of, and about which our Knowledge, concerning Substances, is most employ'd, are those of their secondary Qualities; which depending all (as has been shown) upon the primary Qualities of their minute and insensible parts ... 'tis impossible we should know, which have a necessary union or inconsistency one with another. (IV.iii.11)

And again later,

But our Minds not being able to discover any connexion betwixt these primary qualities of Bodies, and the sensations that are produced in us by them, we can never be able to establish certain and undoubted Rules, of the Consequence or Co-existence of any secondary Qualities, though we could discover the size, figure, or motion of those invisible Parts which immediately produce them ... there is no conceivable connexion betwixt the one and the other. (IV.iii.13)

Locke's argument seems to be that because the causal powers of the primary qualities of bodies vis à vis the secondary qualities are inconceivable, then there is no conceivable explanation of how the primary qualities produce the secondary quality ideas, therefore, there are no rules - within the grasp of our cognitive abilitiesfor their prediction. That is, because of this ignorance, even if we knew both the secondary qualities and the corpuscular structures of bodies, we should still lack any rules for associating those physical features with their effects on us. But since both the top-down and bottom-up theses assume that there exist (though humanly unknowable) such rules, they are both based on assumptions about matters of fact that lay (both empirically and conceptually) beyond our ken. 
Here Locke is calling into question the conceptual possibility of both a humanly knowable and explanatory connection between secondary quality ideas and primary quality ideas. He takes this to imply that it is entirely possible for two objects to share nominally essential properties, but differ in internal constitutions; objects sorted into the same species by nominally essential properties may be "in their internal Constitution, as different from one another, as several of those which are ranked under different specifick Names" (III.x.20). Indeed, in III.vi.20 and III.vi.39 Locke assumes the point at issue: different configurations of clocks could all be classified together as clocks, regardless of their internal compositional differences. For Locke, there is no reason to assume a priori that any particular variation in the internal mechanisms should constitute a species difference; and it should not be forgotten that this argument is intended to be an analogy with corpuscular structures.$^{33}$ So, by Locke's lights, the top-down thesis is unjustified; even assuming the mechanical hypothesis, sameness of observable qualities need not imply sameness of internal constitutions.

Conversely (and most importantly for my argument), our nescience goes the other way too. ${ }^{34}$ Given what Locke argues above in III.x.20 and IV.iii.13, he has given us powerful reasons to think that sameness of internal physical constitutions does not imply sameness of observable qualities. In claiming that members of kind K1 could have either real essence E1 or E2 or En (as he does in III.x.20), Locke is asserting that the assumptions we make about the causal laws when classifying according to the top-down thesis may not always neatly track the physical reality. Moreover, as I argued above, if there are no conceivable connections between the physical causal ground of the observable qualities of bodies, and thus no knowable rules for the consequence or coexistence of observable qualities-even given a knowledge of their physical ground-it follows that by Locke's lights there is no reason to suspect that similar internal physical constitutions must produce similar observable qualities. Thus, for Locke, from our necessary ignorance of the actual causal laws and our ignorance of the totality of corpuscular reality, we cannot justifiably claim either that all or only instances of E1 are members of K1 (which cuts against the bottom-up thesis) any more than we can justifiably claim that only members of K1 have E1 (which cuts against the top-down thesis). The bottom-up thesis dies by the same sword as the top-down thesis.

Indeed, his rejection of the bottom-up thesis is assumed in IV.xii.12 where he says that "we cannot from a Discovery of their real Essences, grasp at a time whole Sheaves; and in bundles, comprehend the Nature and Properties of whole Species together." ${ }^{35}$ Knowledge of a collection of real essences fails to yield knowledge of which individuals are to be sorted into the same species. If the real essence is the cause of the properties of a body, and - let us suppose-that all bodies with the same real essence have the same properties (that similarities in real essence implies similarities in observable qualities), then why should we be unable to sort bodies even if we had knowledge of their real essences? The answer for Locke seems to be that similarities in internal constitutions need not imply similarities in observable 
qualities; that is why human knowledge of real essences alone will not allow us to determine the boundaries of species and sort individuals, or as Locke put it, "grasp at a time whole sheaves." Similarly, knowledge of real essences will not allow us to comprehend the natures and properties of whole species is because-for all we know-similar internal constitutions can be sorted into different species, as determined by nominal essences. If Locke thought there could be natural species à la Phemister and Stuart where micro-structural similarities nearly always matched up with observable similarities, then there would be no reason to think we should not know in bundles the natures and properties of whole species by discovering their real essences. But this is just what Locke rejects. This is why, in III.vi.19, Locke argues that even if we thought that species were determined by real essences, we would still not know which collections of observable qualities would co-vary with which internal structures.

Of course, while it is possible to argue that Locke thought that observable qualities are plausibly thought to be caused by the corpuscular structures of bodies (which the new science of mechanism and the bottom-up and top-down theses are committed to), from this it does not follow that he thought that there was an a priori reason to assume that similarity in corpuscular structure implied similarity in causal powers or vice versa. That is, Locke can insist that the causal dependence of observable qualities on the corpuscular structure is theoretically useful for the new science and intelligible in the sense above (even if the crucial causal story is not), without thereby committing himself to the truth of the theory, i.e., to the claim that differences in observable qualities must actually be accompanied by differences in corpuscular structure. If Locke thought the causal story worked just in the bottom-up cases so that sameness of internal constitutions were likely to cause sameness of observable qualities, then Locke could claim that knowledge of real essences would allow us to justifiably sort objects into species, but as we have seen above, he denies this.

Since knowledge of the necessary connections between the ideas of secondary qualities and the physical constitution is impossible, it follows that, as far as we know, similarity in real constitution does not guarantee similarity in observable qualities, and so no knowledge of the nature and properties of a whole species can be grasped by knowing the real essence of either a particular instance or a group of putative instances. So there is no reason to think that real essences in se could constitute and demarcate kinds. If this argument is correct, and Locke denies the theoretical assumption that similarity in structure fails to justify our inferences to similarity in observable effects and vice versa, then it is clear why Locke would reject the top-down and bottom-up theses as theoretically justified by the new science of mechanism. ${ }^{36}$

This is why Locke says in III.vi.20 (referring to III.vi.19) that "our distinguishing Substances into Species by names, is not at all founded on their real essences; nor can we pretend to range and determine them exactly into species, according to internal essential differences." ${ }^{37}$ Moreover, it is the conceptual and epistemic 
gap that explains why our terms do not refer to the real essences and explains why the assumption that the same internal constitution always accompanies the bodies sorted under the same species name is mistaken:

That which, I think, very much disposes Men to substitute their names for the real Essences of Species, is the supposition before mentioned, that Nature works regularly in the Production of Things, and sets the Boundaries to each of those Species, by giving exactly the same real internal Constitution to each individual which we rank under one general name. Whereas anyone who observes their different Qualities can hardly doubt, that many of the Individuals, called by the same name, are, in their internal Constitution, as different one from another as several of those which are ranked under different specifick Names. This supposition, however, that the same precise and internal Constitution goes always with the same specifick name, makes Men forward to take those names for the Representatives of those real Essences; though indeed they signify nothing but the complex Ideas they have in their Minds when they use them. So that, if I may so say, signifying one thing, and being supposed for, or put in the place of another, they cannot but, in such a kind of use, cause a great deal of Uncertainty in Men's Discourses; especially in those who have thoroughly imbibed the Doctrine of substantial Forms, whereby they firmly imagine the several Species of Things to be determined and distinguished. (III.x.20)

While Locke only notes the fact that similar observable qualities need not indicate similar internal constitutions (the top-down thesis), it is important to see that the problem would be the same for anyone who thought that similar internal constitutions imply similar observable qualities (the bottom-up thesis); the mistake Locke is pointing out is the fundamental one of presupposing the bottom-up thesis embedded within the mechanical hypothesis as a reason to take the observable qualities as the signs of the real essences (the top-down thesis). And surely, if Locke thought that real essences were singled out by the nominal essences and that the observable qualities generally co-varied with the real essences, then there would be no reason to rule out the possibility that species of this sort would be possible, but he does.

Of course, there are the passages in II.xxx-Xxxi where Locke appears to assume that similar secondary quality ideas have external causes that are structurally similar, e.g., II.xxx.2. There is no reason, however, to think that these passages are at odds with my thesis. First of all, this part of Book II does not argue that the mechanical hypothesis is true, but is more of a discussion of the limits of our ideas of substances. Secondly, while it is true that in II.xxx-xxxi Locke holds that God superadds certain powers (secondary and tertiary qualities) to the individual primary quality structures of bodies, this is, however, compatible with there being a variety of types of micro-structural causes of some qualitatively identical simple ideas of secondary qualities, or a variety of secondary quality ideas produced by the same type of micro-structure. That is, the assumption of the intelligibility or plausibility of causal dependence (even with steady correspondence) is not equivalent to asserting the truth of causal dependence cum universal co-variance. Moreover, 
as we saw in IV.iii.25, even though Locke argues that a priori knowledge of the tertiary qualities (i.e., the mechanical effects) of bodies would be possible if we had epistemic access to the primary qualities of their internal constitutions, there is no suggestion here that Locke thinks that knowledge of the primary qualities of the internal constitution would yield any knowledge of their resulting secondary quality ideas. That seems to be one of the conclusions of IV.iii.12-14 as well; knowledge of the real constitutions does not yield knowledge of their effects. If Locke envisioned the connection as necessarily including causal dependence cum universal co-variance, then he should have concluded that knowledge of the primary qualities could yield knowledge of their necessarily resulting secondary qualities, but this is just the opposite of what we find. What this shows is that, not only do the internal constitutions - even of sorted individuals - fail to determine species, but that Locke thought that realists about corpuscular species could not justify their practice of assuming that the observable qualities are our window into the deep structure because the crucial connection is inconceivable—not simply unknown. ${ }^{38}$

\section{THE INTELLIGIBILITY OF 'LOCKEAN NATURAL KINDS'}

On the reading of Locke that I am pushing, natural kinds based on similarities of real essences are unintelligible. As we know, real essences for Locke are in principle unknowable to us because there is no humanly conceivable account of the necessary connection between the corpuscular structure and the secondary qualities, which constitutes part of the concept of real essences. Therefore, by Locke's lights, we cannot include the real essences in our account of species differentia; even if we could come to know the internal constitutions, we should still be necessarily ignorant of the connections between the physical structures of bodies and their powers that constitute the bulk of our knowledge and interests concerning these substances. It appears, then, that Locke is arguing that the supposed causal connections between internal constitutions and nominal essences cannot play the justificatory role they are intended to. According to Locke then, natural kind theories that take the bottom-up thesis to ground our top-down species determinations must fail because there is no way to bridge the conceptual gap between the deep structure and the observable properties.

Moreover, Locke recognized the semantic consequences of the unjustifiable supposition that similarities among the real constitutions ground the phenomenal similarities of members of the same species (as determined by nominal essences); we do not refer to real essences with our species terms. As he put it,

This supposition, however that the same precise internal Constitution goes always with the same specifick name, makes Men forward to take those names for the Representatives of those real Essences, though indeed they signify nothing but the complex Ideas they have in their Minds when they use them. So, that, if I may so say, signifying one thing, and being supposed for, or put in the place of another, they cannot but, in such a kind of use, cause a great deal of Uncertainty in Men's Discourses. (III.x.20; his italics) 
Locke identifies this supposition as an abuse of words (III.x.18); terms are not meaningful when they cannot be attached to ideas and we have no ideas of real essences, and thus cannot refer to them. The reason we can speak meaningfully of real essences in Locke, then, is only because our ideas of them consist only of a definite description of the type "the $\mathrm{x}$ that is the internal constitution of the object $O$, that plays role $R$ in explaining and causing properties, $\mathrm{p}^{l}-\mathrm{p}^{n}$." Nevertheless, we still necessarily lack any ideas of particular real essences. ${ }^{39}$

Since, by his lights, general ideas are formed by abstraction and we cannot possibly come to possess any ideas of individual real essences, then a fortiori, there are no possible abstract ideas of groups of real essences (III.vi.19). And since we do not refer to real essences with our species terms (III.x.20), it is thus unintelligible to attempt to refer to species of real essences. There is no intelligible way to connect our nominal essence ideas to a theoretical posit like real essences (except by the above type of description), and this is what renders our ignorance of species-in any sense other than in terms of nominal essences-incurable.

\section{CONCLUSION}

The upshot of all of this is that, by Locke's lights, real essences cannot play a role in corpuscularian accounts of species because (i) similarity of structure in se does not classify, only nominal essences do; (ii) Locke rejects the possibility that we could justify the bottom-up thesis, i.e., our supposition that similarity in the corpuscular constitutions of the real essences implies similarities in observable qualities; and (iii) since human knowledge of particular real essences is in principle impossible, and that the term 'real essence' fails to refer to individual, or classes of, real essences, it follows that we can have no knowledge of classes of real essences. The moral of this story is that we cannot intelligibly speak of natural species in Locke's Essay in either Phemister's or Stuart's sense. ${ }^{40}$

\section{ENDNOTES}

1. "'tis past doubt, there must be some real Constitution, on which any collection of simple Ideas co-existing must depend. But it being evident, that Things are ranked under Names into sorts or Species, only as they agree to certain abstract Ideas, to which we have annexed those Names, the Essence of each Genus, or Sort, comes to be nothing but that abstract Idea, which the General, or Sortal . . Name stands for" (III.iii.15). On a terminological note, the abstract idea that species names stand for he calls a nominal essence, the real constitution cited as the causal ground of the properties of a body he calls a real essence.

2. For a different account of Lockean natural kinds, see Conn 2002.

3. In defense of this Stuart cites III.vi.6.

4. As Stuart (1999, 289-291) and Phemister (1990, 51-52) point out, there may be circumstances where similarity in internal constitution does not guarantee similarity in observable qualities, but that Locke does take it to be plausible, so the inference must be taken to be 
fallible in this sense. I describe this as a corpuscular or structural similarity because, as I argue below, there is an important distinction for Locke between internal constitutions and real essences. See also Stanford 1998; Goodin 1998.

5. Christopher Conn $(2002,480)$ accepts something like the top-down and bottom-up theses. By his lights, since both the similarities among the observable qualities of bodies and their micro-structural causes are objective similarities, then a "Lockean species, or kind, is a class of phenomenally (and hence structurally) similar objects." But since his account has certain relevant differences from the two presently under consideration, pursuing his version would take us too far afield. Nevertheless, it seems to me that his account founders on the same problem: Locke does not believe that the bottom-up thesis is justifiable.

6. Locke's reply to Molyneux's letter, dated 20 January 1693, no. 1592. It is important to note that Locke commits himself to the existence or real constitutions, but he does not commit himself to the existence of real essences. If he believed that his ontology included both real essences and natural kinds of real essences, this would be an ideal opportunity for him to make that clear, but his failure to do so should count against the realist reading.

7. See also III.vi.30-31 and II.xi.6.

8. It should be noted in favor of my account that Leibniz too thought that Locke should have drawn the conclusion that bodies that are phenomenally similar should also be similar in their deep structure (and vice versa), but was convinced that Locke had not. In the Nouveaux Essais Leibniz argues that the resemblances natural objects bear to each other are both natural and objective, and since the foundation of species and genera are rooted in natural similarities, then our species determinations are all rooted in nature: "generality consists in the resemblance of singular things to one another, and this resemblance is a reality." (Leibniz 1996, 292) Locke's unwillingness to draw this conclusion perplexed Leibniz: "I do not see why you have returned to the attack on genera, species and forms, since you too have to recognize genera and species and even inner essences and forms." (Leibniz 1996, 322)

9. As I argued above, Locke takes it that the virtue of the mechanical natural philosophy is that - unlike scholasticism - it grounds all our explanatory entities in empirically familiar kinds of objects and relations, but no matter how intelligible and superior the mechanical hypothesis, we have philosophical reasons for thinking that the primary qualities of bodies cannot play the causal and explanatory roles they were intended to. So, while it is legitimate for the mechanist to say that the physical features of bodies ground the observable powers of bodies, how they do so is not intelligible to us, and so there are deep gaps in the theory. So Locke can make a distinction between what makes sense, given the mechanical theory, and what makes sense philosophically and semantically. If my reading of Locke is correct, what Locke is arguing is that the mechanical natural philosophy is intelligible, and it assumes the truth of the bottom-up and top-down theses, but neither of these theses can do the philosophical work they are intended to.

10. This is why Locke, in the chapter titled "The Improvement of our Knowledge," insists that ideas about the coexistence and incompatibility of qualities are only experimentally achievable. See, for example, IV.xii.11-12. See also III.vi.28-29.

11. "I have here instanced in the corpuscularian Hypothesis, as that which is thought to go farthest in an intelligible Explication of the Qualities of Bodies" IV.iii.16.

12. Rozemond and Yaffe $(2004,390-397)$ argue — rightly — that this passage does not show that Locke believed that mechanical explanations could yield demonstrations in natural 
philosophy akin to those in mathematics, but that does not militate against my point here. What I am arguing is that Locke thought that, irrespective of their shortcomings, mechanistic accounts of the tertiary qualities of bodies are more intelligible than Scholastic accounts because of the empirical moorings of their fundamental concepts.

13. Even though Locke thinks that the causal powers of primary qualities to produce physical changes in other bodies are intelligible, he also says in II.xxiii.28 that we cannot explain how physical bodies cause these changes in each other: "Another Idea we have of Body, is the power of communication of Motion by impulse; and of our Souls, the power of exciting Motion by Thought. These Ideas, the one of Body, the other of our Minds, every days experience clearly furnishes us with: But if here again we inquire how this is done, we are equally in the dark. For, in the communication of Motion by impulse, wherein as much Motion is lost to one Body as is got to the other, which is the ordinariest case, we can have no other conception, but of the passing of Motion out of one Body into another; which, I think, is as obscure and unconceivable, as how our Minds move or stop our Bodies by Thought, which we every moment find they do." So, for Locke, the intelligibility of mechanical explanations cannot rest on their purported ability to show how physical causes produce their effects. Rather, their intelligibility seems to rest solely in the familiarity of the entities and processes invoked to explain the phenomena. See Downing 1998.

\section{Elements of Natural Philosophy, III 304f.}

15. See, for example, IV.iii.13: "But our Minds not being able to discover any connexion betwixt these primary qualities of Bodies, and the sensations that are produced in us by them, we can never be able to establish certain and undoubted Rules, of the Consequence or Co-existence of any secondary Qualities, though we could discover the size, figure, or motion of those invisible Parts which immediately produce them ... there is no conceivable connexion betwixt the one and the other."

16. For contrary opinions, see Ayers 1996; Woolhouse 1971.

17. And it appears that in III.vi.16 Locke recognizes this distinction: "I have here instanced the corpuscularian Hypothesis, as that which is thought to go farthest in an intelligible Explication of the Qualities of Bodies; .. . This at least is certain, that which ever hypothesis be clearest and truest, (for it is not my business to determine, . ...." Locke explicitly rejects the idea that he is arguing for the truth of the mechanical hypothesis but does endorse its superior intelligibility.

18. Of course there is a difference between the completeness and truth of a theory, and one might respond by arguing that the fact that the phenomena of cohesion, impact, secondary qualities and gravitation are left unexplained by the mechanical hypothesis only shows that the theory is incomplete, not false. Nevertheless, he is arguing that the mechanical hypothesis does not do what it was intended to do, i.e., yield an intelligible account of causation. This is why Locke offers the superaddition thesis in IV.iii.28. Thus, in IV.iii.16 he says that matter in motion "go farthest in an intelligible Explication of the Qualities of Bodies" because the explanans are intelligible-empirically grounded-entities, not because there are no explanatory gaps.

This also explains why, immediately after identifying the mechanical hypothesis as going the farthest in providing us with intelligible explanations of natural phenomena, he says: "I fear the Weakness of humane Understanding is scarce able to substitute another [explanatory theory], which will afford us a fuller and clearer discovery of the necessary Connexion, and 
Co-existence, of the Powers, which are to be observed united in several sorts of them." (IV. iii.16) The gap between reality and our best explanatory theory reveals the deep nescience about causation in nature we must accept; our explanatory theories are incomplete-perhaps even false-because we lack the kinds of ideas and concepts that would render intelligible how the body-body, mind-body and body-mind interactions actually obtain. This is surely not a ringing endorsement of either the truth or the epistemological adequacy of the mechanical hypothesis.

19. For more of the debate on the strength of the mechanical hypothesis in Locke, see Ayers 1981; McCann 1985; and Wilson 1979.

20. See III.ix.14 and 17. See also Judith Crane 2003, 249-259, esp. 256-257.

21. Lisa Downing (1992) argues that by Locke's lights corpuscles are not in principle unobservable. This implies that real essences are not reducible to just corpuscular constitutions.

22. For more on this, see Rozmond and Yaffe 2004. Although I do not agree with everything in their article, I am grateful that they did all of the necessary spadework for my argument, and in particular, I think that they are correct in concluding that for Locke the notion of real essences, understood in either a corpuscular or Scholastic manner, does no work in natural philosophy. I should also note here that I am only examining real essences in the mechanical sense, not in the sense of substantial forms.

23. I thank one of the anonymous referees for pointing out the need to make this clear.

24. Locke, in III.vi.8, also seems to indicate this same conclusion. See Ayers 1996 (II), 67-98; Guyer 1995, 133; and Stanford 1998. For Ayers and Guyer, the real essence is a subset of the structure that explains its possession of its nominally essential properties. Stanford, however, argues that real essences also include the necessary connections between the real constitution and the nominally essential properties. For dissenting views, see Woolhouse 1971, 113-114; Mackie 1976, 78; Phemister 1990; and Shapiro 1999.

25. To be clear, in III.iii.15 we see Locke defining two kinds of essences, real and nominal, and as I argue below, he then explains why the real essence, thusly understood, fails to ground any theories of natural species. So, it is not my view that Locke is arguing for some particular version of real essence as the truth, rather, it seems to me that he is simply laying out a definition-one I have previously argued that he sees used in Boyle's work on natural kinds (Jones 2007) — and then rejecting it as inadequate to bear the weight of a theory of natural kinds. The present paper is in some degree a defense of, and expansion of, my interpretation of Locke in that article. For more on the debate over relative real essences in Locke, see Owen 1991. In III.iii.15 we see Locke defining two kinds of essences, real and nominal, and as I argue below, he then explains why the real essence, as it is understood, fails to ground any theories of natural species.

26. In III.vi.19 Locke points out that "We can never know what are the precise number of Properties depending on the real Essence of Gold, any one of which failing, the real Essence of Gold, and consequently Gold, would not be there, unless we knew the real Essence of Gold itself." A possible interpretation of this is that, if there can be properties of a real essence that we cannot know, and properties are distinguished from qualities in that only properties flow from the essence, then it seems that the real essence is not relative to the nominal essence, but is prior to it. Otherwise why conclude with "the real Essence of Gold itself"? This seems to imply that real essences, and thus corpuscular species, exist prior to our nominal 
essence construction, but this would be a mistake. All Locke implies here is that there are effects of the part of the internal constitution that are included within the real essence that we have not yet included in the nominal essence. That is, if the corpuscular sub-structure $S$ of gold (a proper subset of the corpuscular structure of gold) caused malleability, which we include within the nominal essence, it is possible that $S$ also cause some other effect $E$, which though not included in the nominal essence, is caused by $S$, which is part of the real essence, and so $E$ would be a property-strictly speaking - but not one we've included in the nominal essence. This reply is consistent with relativised real essences, but also with my position because we're talking about a sortal concept, i.e., gold.

27. In III.vi.6 Locke appears to restrict his account of real essences to specific properties. I argued above, however, that this cannot be his considered view. Here I follow Stanford (1998) in taking the real essence to include the necessary connection between the internal constitution and its effects.

28. I am limiting my account to the real essences of bodies. For an analogous argument that holds for the real essences of modes, etc., see Stanford 1998. For a different interpretation of this passage, see Ayers 1996 vol. 2, 142-153.

29. In III.xi.23 he reiterates this claim. This passage and IV.vi.11, however, do not refute my contention below. He is saying that if we had knowledge of the real essences- the internal constitutions cum their causal powers to produce qualities - of a collection of sorted particulars then we should know how each one of them produce the nominally essential properties of bodies that we antecedently called 'gold.' This is compatible with there not being any single type of internal constitution correlated with the nominally essential properties of gold. On the other hand, IV.iii.25 is not a counter-example to my thesis that the connections between internal constitutions and the qualities is included in the definition of real essences; here Locke simply maintains that a better knowledge of the primary qualities of substances would allow us to deduce a priori some of their tertiary qualities. But this a priori deduction assumes that knowledge of the primary qualities contains in it something about how primary qualities affect each other. There is no hint here of whether knowledge of the primary qualities alone would yield a priori knowledge of secondary qualities.

30. Notice that in these passages Locke does not employ the technical terms 'nominal essences' or 'species' when talking about what God or angels could deduce a priori. This suggests that real essences are not the real essences of species; otherwise God or angles could surely know their species as well.

31. In IV.iii.10-14 the causal relationship itself between the primary and secondary qualities is inconceivable. Thus, in III.vi.36, Locke's use of 'probably' indicates a nescience-but understandable supposition of the natural orderliness - of relations between the deep structure and the qualities because of what he goes on to argue in III.vi.39; what makes it 'probable' in III.vi.36 is that the most intelligible theory we have-Boyle's-says that it does, not that Locke thinks that this correlation can be either rationally or empirically established. See Yost 1951.

32. This also explains why, in III.vi.28-29, Locke insists that we suppose that nature conjoins qualities, e.g., malleability and heaviness, but that supposition, though natural, is merely a supposition.

33. See also III.vi.8 and III.vi.19. Moreover, as we see in the Stillingfleet dialogue (1829 IV, 433-435), even though the focus was on substantial forms, Locke clearly had the op- 
portunity to assert some kind of species realism, but instead insisted on the classificatory roles of nominal essences. If he had a corpuscularian theory of natural species, there would be plenty of opportunities within his polemics for him to trot it out, but he never does. So, as I have argued, while mechanical explanations are useful, given our limitations they fall short of providing us with knowledge of nature's necessary connections. This is why Locke is able to insist, as in the letters to Stillingfleet and elsewhere, that the phenomenal differences of bodies are reasonably presumed to track structural differences; the most intelligible theory we have says that they should, but since no theory can explain how the phenomenal qualities are produced by these physical structures, then we cannot justify that supposition with the mechanical theory. There is no hint of inconsistency here, only of nescience.

34. For more on Locke's causal skepticism, see Downing 1998, 405-406.

35. Though I recognize that there are other ways to interpret this passage, if my above arguments are correct, then Locke cannot think that a knowledge of real essences alone will yield knowledge of species membership, so an attack on my reading of this passage will also require an attack on my reading of, inter alia IV.iii.13. On a related point, in IV.iii.29 Locke argues that the pursuit of a scientia of bodies that explains the causal powers of bodies is in principle beyond our ken, and so it is lost labor to pursue it. It would be incoherent for him to accept that such knowledge is beyond our capacity yet accept as true one or both of the bottom-up or top-down theses.

36. Of course, some Locke scholars are loath to accept the claim that sameness of internal structure fails to imply sameness of observable qualities. I should point out that both Phemister (1990, 52) and Stuart (1999, 289-292) notice this important part of Locke's antirealism, i.e., that for Locke sameness of corpuscular structure does not imply sameness of observable qualities and vice versa. Both go on, however, to argue for a version of natural kinds in Locke based on the bottom-up thesis anyway. Of course, their arguments assume that Locke's attitude toward the mechanical hypothesis was more sanguine than the Essay warrants.

37. In III.xi.21 he identifies as a false assumption the view that "There are certain precise Essences, according to which Nature makes all particular things, and by which they are distinguished into Species." It is not trivial that he denies both that nature makes individuals according to a precise essence and that individuals thus belong to species because of their essences. It is difficult to attribute the bottom-up thesis to Locke while making sense of these kinds of denials in Locke.

38. Locke's point is to show that there are limits on the explanatory power of the mechanical hypothesis, and one of those limits is our ability to know what observable qualities go with what structures. One might argue that from the fact that Locke only seems to argue that objects that are similar in nominal essences need not be similar in real constitutions it does not follow that objects that are similar in real constitutions need not be similar in nominal essences. But I think this misses the point of the argument. By his lights, we might be able to experimentally justify correlations between certain structures and their observable effects, but correlations are neither "undoubted rules" nor causal connections. Lack of knowledge of the rules, laws or causal connections does not make inferences in one direction any more justifiable than inferences in the other. Lack of knowledge of the rules of chess will not allow one to determine how the pieces on the board came to their present locations any more than one could determine how many moves remain before the game is over. Of course, one may wonder why Locke did not explicitly say this. But it is my argument above that he argued 
for this in several places in Books III and IV; this is why (see for example, III.vi.19) Locke would think that knowledge of real essences would not help us determine species membership because the differences in the properties of two individuals does not guarantee that the real essences are different.

39. On Locke's semantic theory, "Words in their primary or immediate Signification, stand for nothing, but the Ideas in the Mind of him that uses them" (III.ii.2; his italics). Following the work of Walter Ott $(2004,105-107)$, we should say that where ideas of real essences are concerned, what we really have is a string of ideas together with mental acts that provide what little mental content underlies our meaningful use of the expression "real essence." This total thought is of a definite description like the one above. What this shows is that while there are mental contents to which we may attach the expression "real essence," none of these are grounded in the real essences themselves, and thus would be inadequate for de re definitions of species.

40. I thank Nicholas Jolley, Mark Kulstad, Peter Anstey, Craig Walmsley and Pauline Phemister for their helpful conversations on this topic in Locke. An earlier version of this paper was presented at the 2007 South Central Seminar on Early Modern Philosophy held at the University of Tulsa, and I gratefully acknowledge the comments and criticisms of Michael Futch, Andrew Youpa, Stephen Daniel and the other conference participants. Some of the research and writing for this paper was supported by faculty development grants in the Department of Humanities at Southern Virginia University. I am grateful for that support. I am also indebted to the Editor and anonymous referees for their helpful comments and criticism.

\section{BIBLIOGRAPHY}

Ayers, Michael. 1981. "Mechanism, Superaddition and the Proof of God's Existence in Locke's Essay." Philosophical Review 90: 210-251.

_. 1996. Locke: Epistemology and Ontology, 2 vols. New York: Routledge.

Boyd, Richard. 1991. "Realism, Anti-Foundationalism and the Enthusiasm for Natural Kinds." Philosophical Studies 61: 126-148.

Conn, Christopher Hughes. 2002. "Locke on Natural Kinds and Essential Properties." Journal Of Philosophical Research 27: 475-497.

Crane, Judith. 2003. "Locke's Theory of Classification." British Journal for the History of Philosophy 11: 249-259.

Downing, Lisa. 1992. “Are Corpuscles Unobservable in Principle for Locke?” Journal of the History of Philosophy 30: 33-52.

1998. "The Status of Mechanism in Locke's Essay." The Philosophical Review 107(3): 381-414.

Goodin, Susanna. 1998. "Why knowledge of the internal constitution is not the same as knowledge of the real essence and why this matters." Southwest Philosophy Review 14(1): 149-155.

Guyer, Paul. 1995. "Locke's Philosophy of Language." In The Cambridge Companion to Locke, ed. Vere Chappell. Cambridge: Cambridge University Press. 
Jones, Jan-Erik. 2007. "Locke vs. Boyle: The Real Essence of Corpuscular Species." British Journal for the History of Philosophy 15(4): 659-684.

Kornblith, Hilary. 1993. Inductive Inference and its Natural Ground. Cambridge, MA: MIT Press.

Leibniz, G. W. 1996. Nouveaux Essais sur l'Entendement Humain. Ed. Peter Remnant and Jonathan Bennett. Cambridge: Cambridge University Press.

Locke, John. 1829. The Works of John Locke, 10 vols. London: Thomas Teggs.

1975. An Essay Concerning Human Understanding. Ed. P. H. Nidditch. Oxford: Clarendon Press.

Mackie, J. L. 1976. Problems From Locke. Oxford: Clarendon Press.

McCann, Edwin. 1985. "Lockean Mechanism." In Philosophy, Its History and Historiography, ed. A. J. Holland. Dordrecht: Reidel, 209-231.

Ott, Walter. 2004. Locke's Philosophy of Language. Cambridge: Cambridge University Press.

Owen, David. 1991. "Locke on Real Essences." History of Philosophy Quarterly 8: $105-118$

Phemister, Pauline. 1990. "Real Essences in Particular." Locke Newsletter 21: 27-55.

Rozemond, Marleen and Gideon Yaffe. 2004. "Peach Trees, Gravity and God: Mechanism in Locke." British Journal for the History of Philosophy 12(3): 387-412.

Shapiro, Lionel. 1999. "Toward 'Perfect Collections of Properties': Locke on the Constitution of Substantial Sorts." Canadian Journal of Philosophy 29(4): 551-592.

Stanford, P. Kyle. 1998. "Reference and Natural Kind Terms: The Real Essence of Locke's View." Pacific Philosophical Quarterly 79(1): 78-97.

Stuart, Matthew. 1999. “Locke on Natural Kinds.” History of Philosophy Quarterly 16(3): 277-296.

Wilson, Margaret. 1979. "Superadded Properties: The Limits of Mechanism in Locke." American Philosophical Quarterly 16: 143-150.

Woolhouse, Roger. 1971. Locke's Philosophy of Science and Knowledge. Oxford: Blackwell.

Yost, R. M., Jr. 1951. "Locke's Rejection of Hypotheses about Sub-Microscopic Events." Journal of the History of Ideas 12(1): 111-130. 